\section{SP0091 HOW TO SUPPORT YOURSELF QUITTING SMOKING}

Marios Kouloumas. Cyprus League Against Rheumatism, Aglantzia, Patient Orgnanization, Nicosia, Cyprus

Background: As a person living with Rheumatoid arthritis (RA) (a chronic inflammatory disease caused by both genetic and environmental factors) for the last 45 years (I have been diagnosed with RA at the age of 10 years old) I have been a smoker from the age of 14 years old. As I grew older, and was educated and involved concerning the management of my disease, I realized that smoking, besides its impact on my overall health, had a significant impact as one of the most important risk factors for RA that can increase the severity of the disease and to worsen symptoms. Smoking can also reduce the effect of treatments, including anti-TNF agents and disease-modifying anti-rheumatic drugs (DMARDs). Hence, quitting smoking will improve my overall health, reduce the severity of my disease and ensure that treatments work and reduce the risk for comorbidities e.g. cardiovascular disease and the progression of the disease (joint destructions).

Objectives: To quit smoking after 40 years of being a smoker and to regain my health and quality of life as well as increase the efficacy of the RA treatments.

Methods: To succeed I plan to be very well informed and to understand the reasons of quitting smoking as well as the negative impact of smoking and to realize that quitting smoking will improve my health and social life. To inform all people close to me including family members as well as friends and coworkers about my decision to quit smoking. Mentally being prepared to cope with the desire to smoke as well as ridding the thought of "just smoke one". It is also important to rid the mind and lose the connection of things associated with smoking, for example while drinking coffee. To ask for support if needed and to use tools to stop thoughts of smoking and to cope with the effects of nonsmoking and to try avoiding places that could increase my risk of starting to smoke again e.g. pubs

Results: I have started to cut down on smoking and to minimize it and finally to fully quit smoking for the last 2 years.

Conclusion: Although, if you ask all smokers how difficult it is to stop smoking, the answer will unanimously be "very hard", as a former smoker I can say that if you quit smoking, be aware of the reasons and the importance of quitting smoking and you will notice that after all it is not very difficult. Of course, when you set this goal it is important that in case of first time failure to not blame yourself and I can not stress enough how important a support system is for example that of your friends, family and especially your spouse.

Disclosure of Interests: None declared

DOI: 10.1136/annrheumdis-2019-eular.8520

THURSDAY, 13 JUNE 2019

15:30:00 - 17:00:00

\section{Scientific data visualization: focus on (poster) presentation}

\section{SP0092 'SCIENTIFIC DATA VISUALIZATION: FOCUS ON (POSTER) PRESENTATION}

Maarten Boers. Amsterdam University Medical Centers; Vrije Universiteit, Epidemiology and Biostatistics; Amsterdam Rheumatology and immunology Center, Amsterdam, Netherlands

This practical skills session introduces the principles of good graph and table design as pioneered by Cleveland ${ }^{1}$ and $\mathrm{Tufte}^{2}$ and updated by $\mathrm{Few}^{3}$, this year focusing especially on (poster) presentation.

Its learning objectives include:

- choosing the data visualization that best fits the data

- identifying the basics of table and graph design

- choosing tables and graphs that tell the story in the data

- introduction to poster design

The session is linked to a special poster tour devoted to poster design on the next day:

Poster tour 'F00' (note: this may be a temporary number), Friday 14-06-19, 11:5013:30 (signup required!).

Basics of table and graph design are also covered in my introductory YouTube clips on the ARD website (ard.com).

Direct link: https://www.youtube.com/playlist? list=PLXU14EQbU_V9JpmolAKsaCCOVjJzbxzAN

Also, l've recently published two articles on table and graph design which are freely downloadable. ${ }^{4,5}$

When you download, don't forget the online appendices, because they contain many useful examples!
REFERENCES:

[1] Cleveland WS. The elements of graphing data: Hobart Press, Summit, NJ, USA; 1994.

[2] Tufte E. The visual display of quantitative information. 2nd ed: Graphics Press, Cheshire, CT, USA; 2001

[3] Few S. Show me the numbers. Designing tables and graphs to enlighten. 2nd ed: Analytics Press, Oakland, CA, USA; 2012.

[4] Boers M. Graphics and statistics for cardiology: designing effective tables for presentation and publication. Heart 2018;104:192-200 direct link: http:// heart.bmj.com/cgi/content/full/heartjnl-2017-311581.

[5] Boers M. Designing effective graphs to get your message across. Ann Rheum Dis 2018;77:833-9. direct link: http://ard.bmj.com/cgi/content/full/ annrheumdis-2018-213396

Disclosure of Interests: None declared

DOI: 10.1136/annrheumdis-2019-eular.8431

THURSDAY, 13 JUNE 2019

15:30:00 - 17:00:00

\section{Should we worry about anything else; also young people have multi-morbidities}

\section{SP0093 MANAGING MORE THAN RMDS}

Kristien Van der Elst. University Hospitals Leuven, Rheumatology, Leuven, Belgium

Increasing emphasis has been placed on the concept of multi-morbidity or the coexistence of two or more chronic diseases in adult patients with rheumatic conditions. A few years ago a EULAR initiative raised some points to consider for management of comorbidities, such as cardiovascular diseases and depression, in chronic inflammatory rheumatic diseases in daily practice (1). Nevertheless improved management of comorbidities, including prevention, remains a commonly identified unmet need in rheumatology (2). Multi-morbidity can be quite challenging to manage, while the perspective of the individuals having to cope with multiple chronic diseases could differ from that of health professionals taking care of them. Awareness and regular assessment are key, as well as a collaboration between health professionals and well-informed patients. This lecture aims to provide practical information about how to manage more than the rheumatic disease as such, focussing as well on topics of specific interest to young people.

\section{REFERENCES:}

[1] Baillet, et al. Points to consider for reporting, screening for and preventing selected comorbidities in chronic inflammatory rheumatic diseases in daily practice: a EULAR initiative. Ann Rheum Dis. 2016

[2] Winthrop, et al. Unmet need in rheumatology: reports from the Targeted Therapies meeting 2018. Ann Rheum Dis. 2019

Disclosure of Interests: None declared DOI: 10.1136/annrheumdis-2019-eular.8606

\section{SP0094 \\ DISEASES ON SALE - HOW I DEAL WITH ALL MY CONDITIONS}

Tanita-Christina Wilhelmer. Österreichische Rheumaliga, Austria

In her speech Tanita will explain how she experiences life with multiple conditions There are a lot more than just symptoms of the main condition and emotions to deal with. Although being diagnosed with Adult Onset Stills Disease (AOSD), she suffers from additional morbidities. Like many other young people with RMD's she has to manage all conditions at once. The list of comorbidities to "choose from" is very long, but there are some that made it to the top three: fatigue, depression and anxiety.

The obstacles that come with this situation can be personal, interpersonal, concerning work, school or university. More illnesses lead to more doctors appointments, this results in missing work or private events. Helping others to understand the condition and communicating the needs is a big topic, as well as planning ahead and staying positive. Tanita will adress these issues and give best practice examples.

Disclosure of Interests: None declared

DOI: 10.1136/annrheumdis-2019-eular.8619 